DOI: 10.21625/essd.v3iss2.379

\title{
Parametric Thinking in Form-Based Code Evaluation
}

\author{
Yingyi Zhang ${ }^{1}$, Marc Aurel Schnabel ${ }^{1}$ \\ ${ }^{1}$ School of Architecture, Victoria University of Wellington
}

\begin{abstract}
The concept of Form-Based Code is of central importance in American New Urbanism. There is an increasing concern on Form-Based Code's components and adoptions in cities and counties in the USA. This paper aims to extend Form-Based Code's study to high-density cities of Asia. It explores the methodology of embedding parametric thinking into the multi-scenario evaluation of Form-Based Code. The methodology framework is developed by taking advantage of parametric modelling instruments which visualising the coding procedure on software interfaces. Using Tsim Sha Tsui, Hong Kong as the experimental site, the paper concludes with a parametric evaluation system towards a walkable and accessible environment in the volumetric urban morphology of high-density cities.

(C) 2019 The Authors. Published by IEREK press. This is an open access article under the CC BY license (https://creativecommons.org/licenses/by/4.0/). Peer-review under responsibility of ESSD's International Scientific Committee of Reviewers.
\end{abstract}

\section{Keywords}

Parametric; Form-based code; Zoning; Multi-scenario; Evaluation

\section{Introduction}

New Urbanism movement has arisen since the 1980s. It promotes environmentally friendly habits by creating walkable neighborhoods containing a wide range of housing and job types (Boeing et al., 2014). The principles of New Urbanism, such as walkability and pedestrian-friendly community, diverse neighborhoods and smart transportation, encourage the re-establishment of mixed-use and sustainable urban development. As a representative approach of New Urbanism, Form-Based Code is increasingly concerned due to its creativity in zoning academia and practice.

Form-Based Code is a land development regulation that fosters predictable built results and a high-quality public space by using the physical form as the organizing principle for the code (Form-Based Code Institute, 2014). In the literature dealing with definition of Form-Based Code, plenty of studies focused on comparing this novel approach with conventional zoning (Parolek, 2008). Conventional zoning describes zoning and urban regualtion by the authority which designates legal areas in a municipality to permit and prohibit land use (Lamar, 2015). In the procedure of zoning development, land use is the primary consideration and foundation. It stems from the emergence of conventional zoning during the early twentieth century. At that time, the goal of public health, safety, and welfare drove zoning to segregate residential districts from industry districts (Kan, 2012). However, with the built municipality increased rapidly, the limitation of conventional zoning emerged. There were problems of over zoning which left the cities those spotty areas which aren't quite residential or commercial (Frost, 1958). In the 1980s, Form-Based Code started to work in urban projects as a critical response to conventional zoning. Just as its name implies, Form-Based Code regards form as the essential consideration rather than land use. Form-Based 
Code is different from conventional zoning in terms of the process by which they are prepared, the substance of the standards they contain, the mechanisms by which they are implemented, and the built form they produce (Parolek, 2008). It is argued that contemporary urban developing flow is a continuous mixture. Form-Based Code that promoted mix-used and continuous growth seems more appropriate to cities today.

One representative Form-Based Code project is the Seaside Code of Florida which developed by Duany PlaterZyberk \& Company. The Seaside Master Plan of Form-Based Code regulated the buildings to ensure the creation of an urban environment similar to that of a small Southern town of the period before 1940 (Duany Plater-Zyberk Co., 1980). This project reflects a core value of Form-Based Code - revival rather than newly-created. Inniss called Form-Based Code as back to the future (Inniss, 2007) due to its idea of protecting urban morphology and space texture. According to Borys' Code Study, there are more than six hundred Form-Based Code projects adopted or in the processing as of February 2017. As an American zoning approach, most of the Form-Based Codes are clustered in the USA. If Form-Based Code has the capability to positively influent on the development of cities and peripheries, we hypothesis that it can bring similar benefits to other areas out of the USA. The research attempts to evaluate Form-Based Code in Tsim Sha Tsui area of Hong Kong in response to the hypothesis.

It is necessary to understand Form-Based Code's zoning method before experimenting with the evaluations. Conventional zoning subdivides land into a series of zones such as commercial or residential and then describe the regulations of each zone through tables and images. Differently, Form-Based Code subdivides "transect" into various zones as $\operatorname{Tn}(n=1,2,3 \ldots)$. It generates regulations and codes through two-dimensional and three-dimensional visualized languages for each zone. In Form-Based Code, transect matrix provides zone types with specific forms. The concept of transect matrix is originally used by naturalists to describe the characteristics of ecosystems and the transition from one ecosystem to another. Duany has applied this concept to human settlements, and since about 2000 this idea has permeated the thinking of new urbanists (Zhang \& Schnabel, 2017; Congress for the New Urbanism, 2016). The transect is described as:

“... it arranges in useful order the elements of urbanism by classifying them from rural to urban. Every urban element finds a place within its continuum. For example, a street is more urban than a road, a curb more urban than a swale, a brick wall more urban than a wooden one, and an alley of trees more urban than a cluster. Even the character of streetlights can be assigned in the transect according to the fabrication from cast iron (most urban), extruded pipe, or wood post (most rural)" (Steuteville, 2009).

Figure 1 presents a standard transect matrix of Form-Based Code from natural zone to the special district, which defines the hierarchical development scales (Kim et al., 2011). T1 represents natural zone without any artificial constructions. T2 to T6 describes a continuous improvement of the artificial degree from rural to urban core zone. Based on the determining of zone types, models can be generated to describe Form-Based Code at the conceptual stage of zoning.

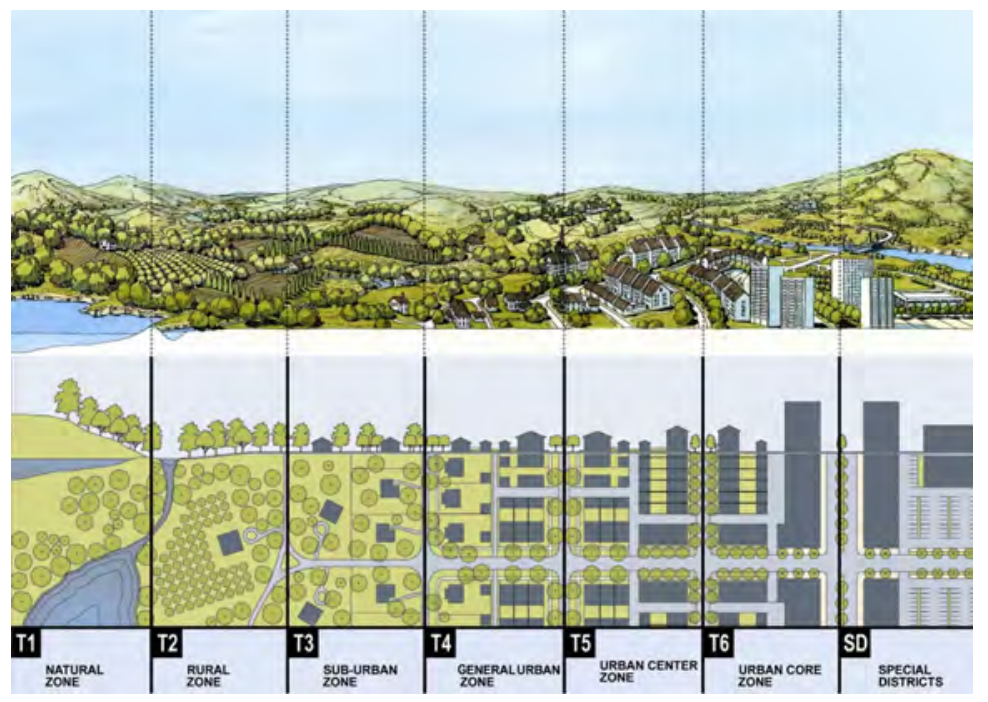

Figure 1. Standardtransect matrix of Form-Based Code 


\section{Form-Based Code Modelling in Context}

Form-Based Code utilizes illustrations and models to describe the zoning intentions, logic and codes. Directly visualized models contribute to the prediction of zoning results. This section provides an attempt on experimenting Form-Based Code in a high-density environment by using Tsim Sha Tsui, Hong Kong as the experimental site. The attempt is supported by an extended transect matrix, a parametric modelling system and a series of Form-Based Code models.

\subsection{Transect Matrix}

Standard transect matrix introduced in the last section describes a general transformation from natural to urban core. A transect is a way of locating and understanding a variety of different types of human settlement within a comprehensive web of natural and human habitats (Bohl \& Plater-Zyberk, 2006). Transect matrix provides a zoning pattern language, not the zoning pattern language. Very different transects could be conceived for cultures and geographic regions where human settlement patterns, and local examples of what constitutes natural, rural, suburban and urban character, have evolved differently (Bohl \& Plater-Zyberk, 2006). Thus, this paper argues an extended transect matrix to suit the experimental site.

In a compact urban environment, the original transect matrix cannot fully express urban forms and space characteristics by only using six zone types. In Tsim Sha Tsui, the communities and neighborhoods are filled with high-density buildings and road networks. Due to limited land resource and a large number of population, all of the communities in Tsim Sha Tsui belong to urban core zone (T6). The indistinctive zone subdivision is meaningless for detailed zoning (Figure 2). Thus, the transect matrix of Form-Based Code needs to be extended to fulfill the zoning requirement of the high-density environment (Figure 3).

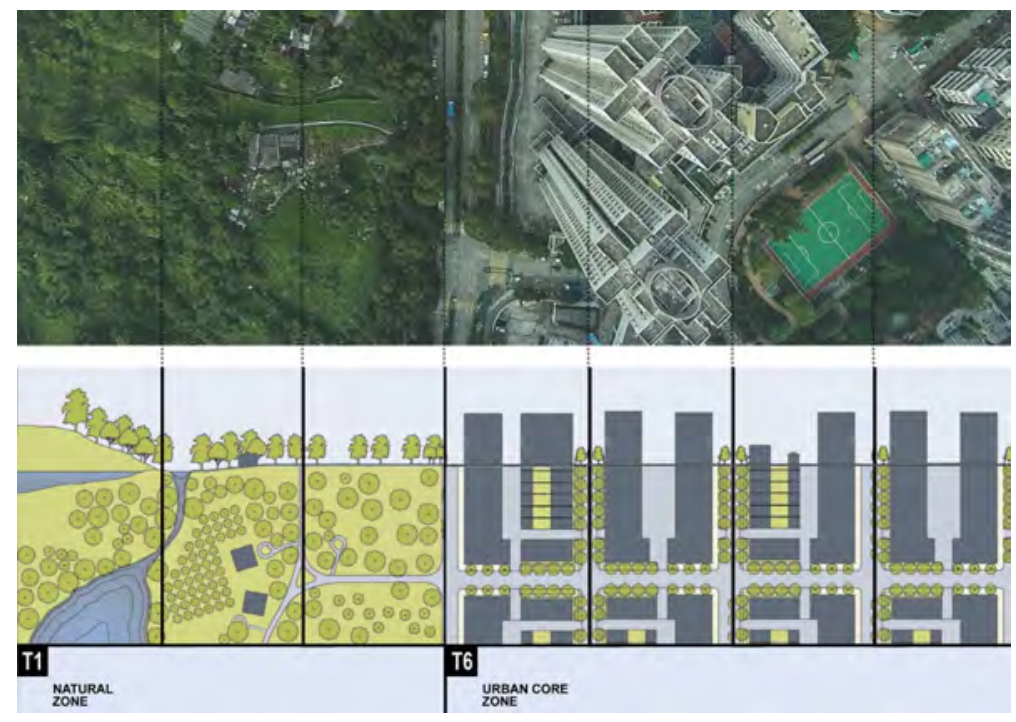

Figure 2. Indistinctive zone type of urban core zone

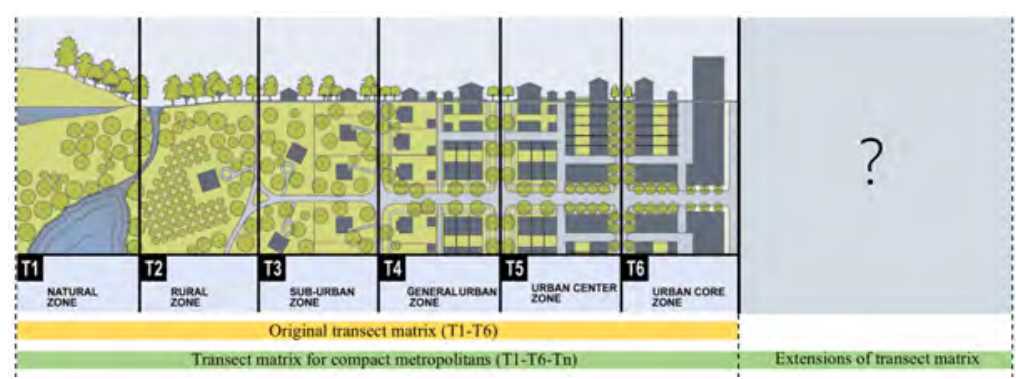

Figure 3. Extensions of the original transect matrix of Form-Based Code 
The extension of transect matrix contains a detailed subdivision of urban core zone (T6). The subdivision aims to describe the zone types of communities in Tsim Sha Tsui with a consideration of form-related variables. Determining the variable categories relies on two principles. First, the variables should be accessible for Form-Based Code team to measure or record. Second, the variables need to have the capability to describe forms of buildings or public space. Accordingly, the paper selects seven variables, including floor area ratio, average pavement width, road hierarchy, infrastructure, depth-width ratio of streets, and max building height, to describe the subtypes of T6.

The variable values are collected during the field study in Tsim Sha Tsui. Floor area ratio is a common index to reflect building density in a certain urban area. For Form-Based Code, higher floor area ratio means closer to the artificial point of transect matrix. Average pavement width refects pedestrian flow. Normally, wider pavement width attracts more usage of pedestrian space. Road hierarchy and infrastructure present the artificial level of an urban area. Depth-width ratio of streets works to describe canyon of Tsim Sha Tsui's streets. Due to the compact morphology, a plenty of streetscapes performed in large depth-width ratio. Max building height is an index that controlled by existing urban regulation documents of Hong Kong. Comprehensively considering these form-related variables, transect matrix is extended and customised for Tsim Sha Tsui as shown in Figure 4. Urban core zone is redefined by six subtypes, including T6-1, T6-2, T6-3, T6-4, T6-5, and T6-6.
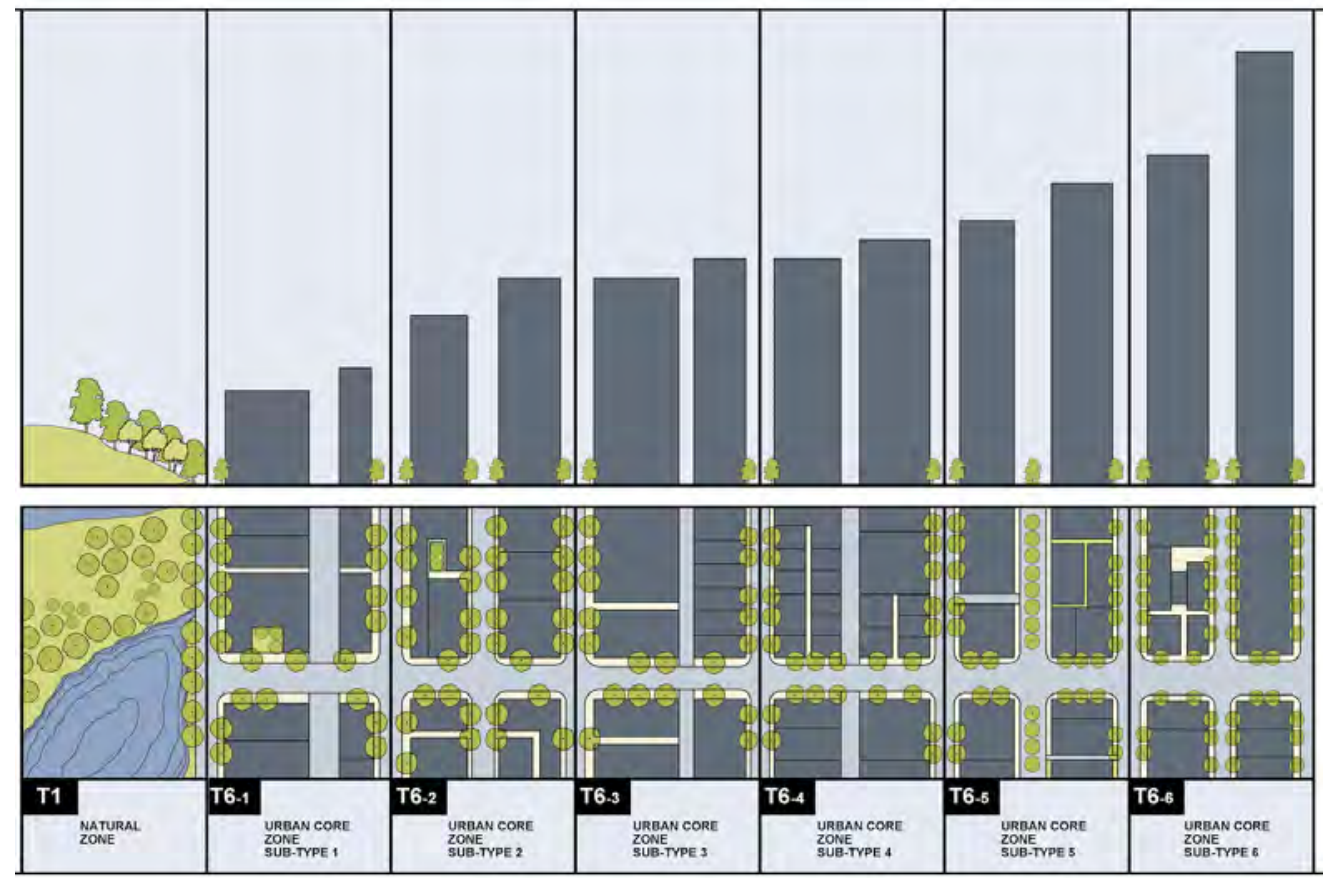

Figure 4. Transect matrix of Tsim Sha Tsui area of Hong Kong

\subsection{Parametric Modelling}

Introducing parametric modelling into Form-Based Code generation procedure makes the zoning results visualized and predictable at the conceptual stage. Parametric concepts are based on algorithmic thinking that enables the expression of parameters and rules that, together, define, encode and clarify the relationship between design intent and design response (Jabi, 2013; Woodbury, 2010). Form-Based Code team can receive a series of roughly simulated models for code visioning and predict possible regulation outcomes through the interface of parametric software.

The subdivision of zone types provides fundamental elements for parametric modelling. These redefined zone types are imported into parametric software Grasshopper $3 D$ towards an integrated system of parameters, zone types, modelling logic, and performance feedback. Grasshopper 3D is a plug-in for Rhinoceros 3D that presents coding in a visualised manner. It offers a programming interface to control geometries. Changing parameters 
causes changes to propagate throughout all functions, and the geometry to be redrawn (Davis, 2013).

The parametric modelling system for Form-Based Code can be simplified as a mode shown in Figure 5. The mode consists of three components, namely in-put, running and ex-put. In-put contains two data resources, zone links and parameters. Each zone type of the extended transect matrix is edited as one link for the modelling system. Embedding the zone links and parameters that need to be controlled in the script, a series of performance feedbacks are reflected on the interface of Rhinoceros 3D. The synthesis scripts combine components and nodes together to establish the modelling logic. Form-Based Code team can manipulate the zone links or parameters to receive real-time models. Figure 6 presents an example of Form-Based Code models from T6-1 to T6-6. The highlight groups in each model describe the location and morphology of different zone types. Model grouping targets to convenient the program modification. It intends to avoid affecting other zone types due to the adjustment. In a real implementation, the performance feedbacks can be diversified according to different parameter settings.

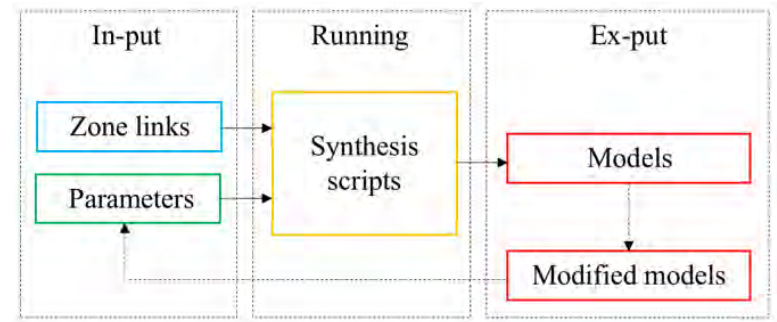

Figure 5. Mode ofparametric modelling system of Form-Based Code
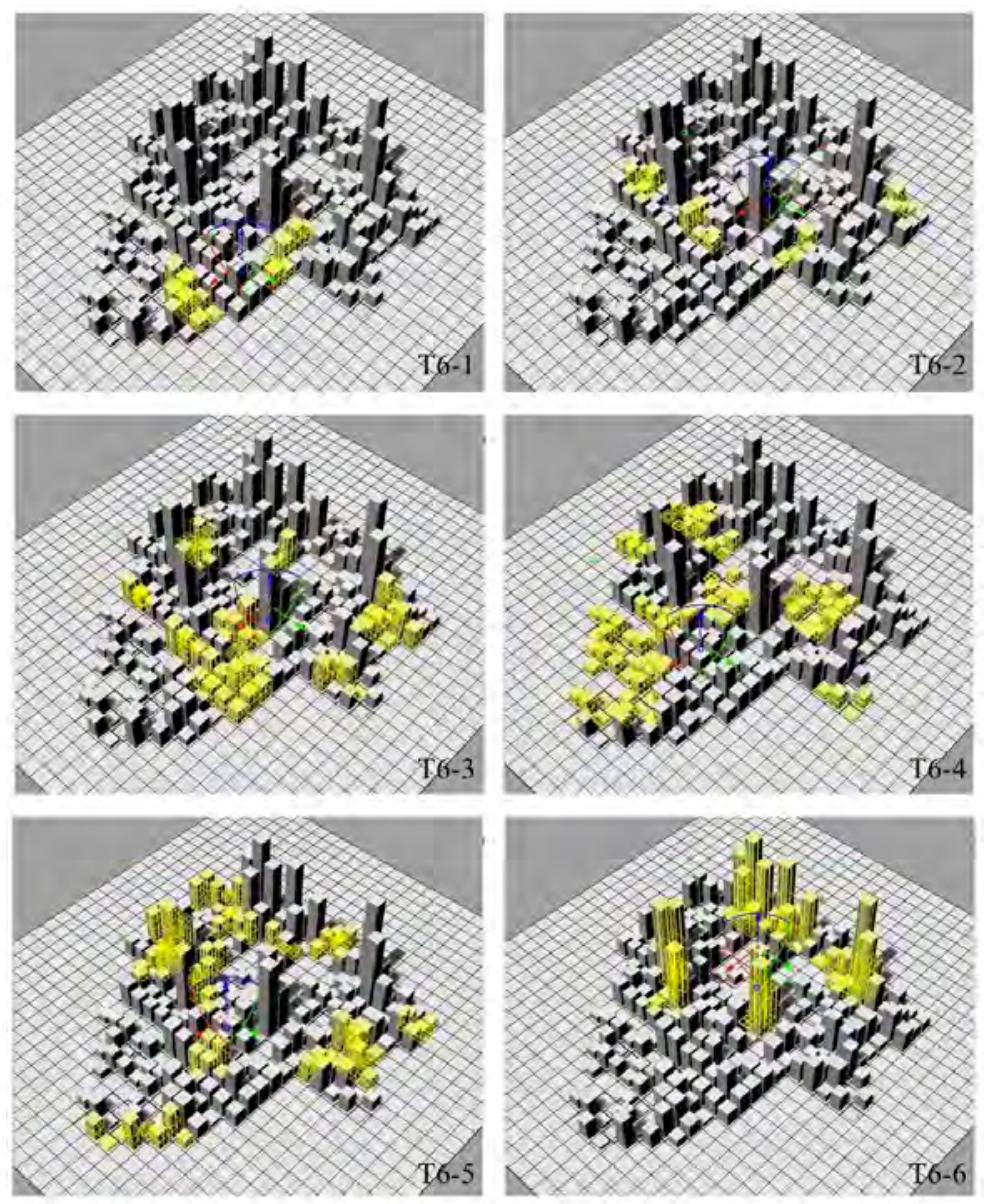

Figure 6. Parametricmodels of zone types

As a high-density urban core zone, Tsim Sha Tsui of Hong Kong has complex urban space developed in a multilevel three-dimensional pattern. Shelton defines the urban space as volumetric. Volumetric means multiple modes 
of movement and varied programs stacked up across many levels, which are above ground and below ground, and where a connection between the level is extremely effective (Shelton et al., 2011). Volumetric pattern happens in compact cities and metropolitans with limited land and excessive population. In Hong Kong, tower and podium consisting of a town centre and single strand connections to isolated "tower neighborhoods" above, in which floors are isolated from each other (Shelton et al., 2011).

Volumetric pattern promotes the development of underground space. On one hand, the large amount of transportation requires efficient rail transit. Compared with the public transportation on the ground, underground development occupies relatively less land resource meanwhile alleviates congestion. On the other hand, the underground space duplicates the above-ground space to create more places for activities. In addition to transportation functions, the underground space can be used as places for commercial, entertainment and leisure. Underground zoning is a significant part of Hong Kong's zoning components. It is necessary to embed underground consideration into the parametric modelling system of Form-Based Code. Figure 7 provides an example of parametric modelling for the volumetric morphology of Tsim Sha Tsui. The above-ground and underground models belong to two separate modelling scripts. Form-Based Code team can obtain the overall model by combining the two systems together. In this study, the structural layer's thickness is not included in the limitation of underground modelling process. Form-Based Code modelling only consider the form-related parameters in this research.

The massing model reflects Form-Based Code intentions through the real-time performances in Grasshopper 3D. In a real implementation, the construction of underground space must follow established urban controls and provisions. Merging underground models into Form-Based Code contributes to the improvement of spatial connections between above-ground and underground to make the two parts as an organic whole in zoning.
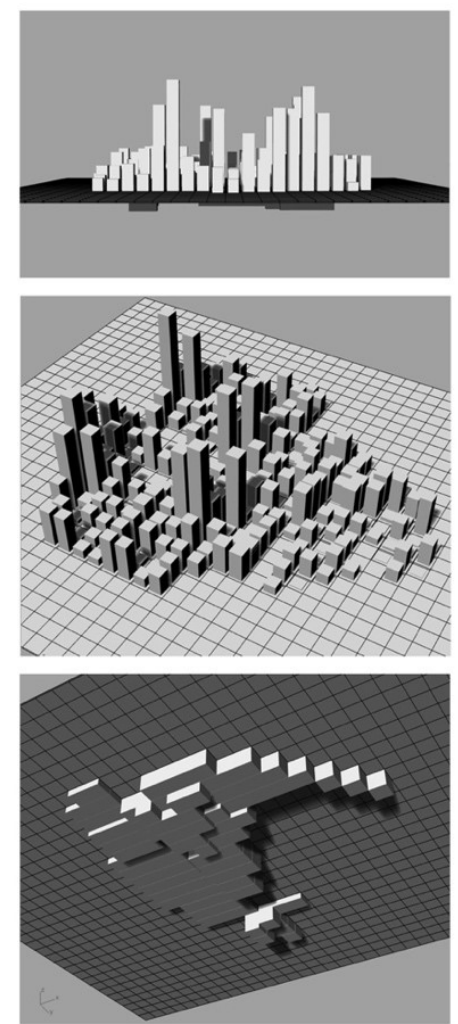

Figure 7. Parametric modelling for the volumetric morphology of Tsim Sha Tsui 


\section{Scenario Evaluation}

Using the parametric model that developed in Grasshopper 3D, this section evaluates the connectivity of the FormBased Code modelling results. Connectivity optimizing works for examining the public space usage and predicting movement routes under Form-Based Code intention in the volumetric morphology. Scenarios evaluations are conducted in the perspectives of street-scale pedestrian movement, underground open space usage and volumetric walkable routes.

In the aspect of street-scale movement, the possible pedestrian flow is simulated by controlling the building coverage rates, setbacks and walkable areas. The elements influencing street-scale regulation are manifold, but walkability is increasingly valued at street canyon and neighbourhood (Zhang \& Schnabel, 2017) especially in high-density cities. As Southworth has presented, not only does pedestrian transportation reduce congestion and have a low environmental impact, it has social and recreational value (Zhang \& Schnabel, 2017). He argues that six criteria for the design of a successful pedestrian network: connectivity; linage with other modes; finely grained land use pattern; safety; quality of path; and path context (Southworth, 2005). In Form-Based Code models, the connectivity is evaluated through parametric thinkings. The research transfers the perceive pedestrian space into the parametric model and analyse the pedestrian movement in algorithm platform.

The component Galapagos of Grasshopper 3D works as the instruments to evaluate connectivity. It uses an evolutionary-based solver to calculate solutions. Using one street-scale site of Tsim Sha Tsui as an example. The site contains part of zone T6-1 and T6-4. A script is written in Grasshopper 3D with the main component Galapagos. Galapagos has two connecting points, Genome and Fitness. They are both for importing information. The Genome is to connect with independent variables. Coordinates of each block or plot are the independent variables, and the length of the connections between the nodes is the part that should be measured through Galapagos (Figure 8).
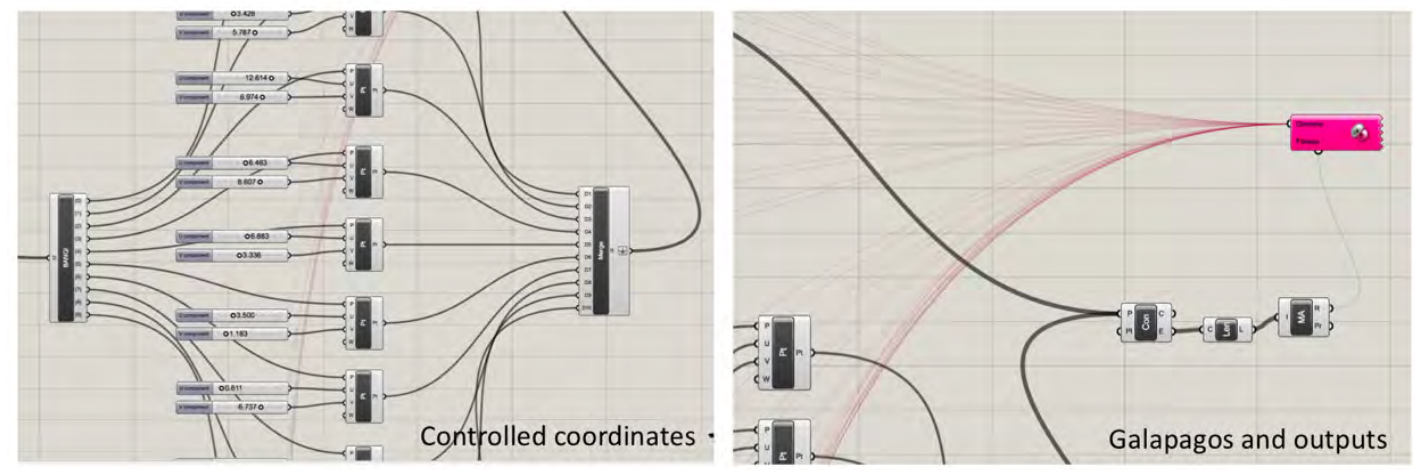

Figure 8. Using Galapagosto control geometry coordinates

The parametric script for optimizing connectivity is described in Figure 9. If assuming the buildings in contexts are regular symmetrical rectangles, they can be simplified as parametric nodes in the modelling process. Through running the Galapagos component, the pedestrians' activity path can be roughly simulated and measured. In the high-density areas of Tsim Sha Tsui, shorter walkable connections between buildings contribute to a convenient and effective pedestrian system. While longer walking paths offer more opportunities for stores being noticed by customers especially in a place with mixed functions of commercial and residential. Galapagos in Grasshopper 3D helps to calculate an appropriate walking distance for pedestrians. When processing the components, Galapagos offers a pop-up screen for changing the options (Figure 10). Form-Based Code team can choose the Fitness type, maximize or minimize, to control the processing results. 


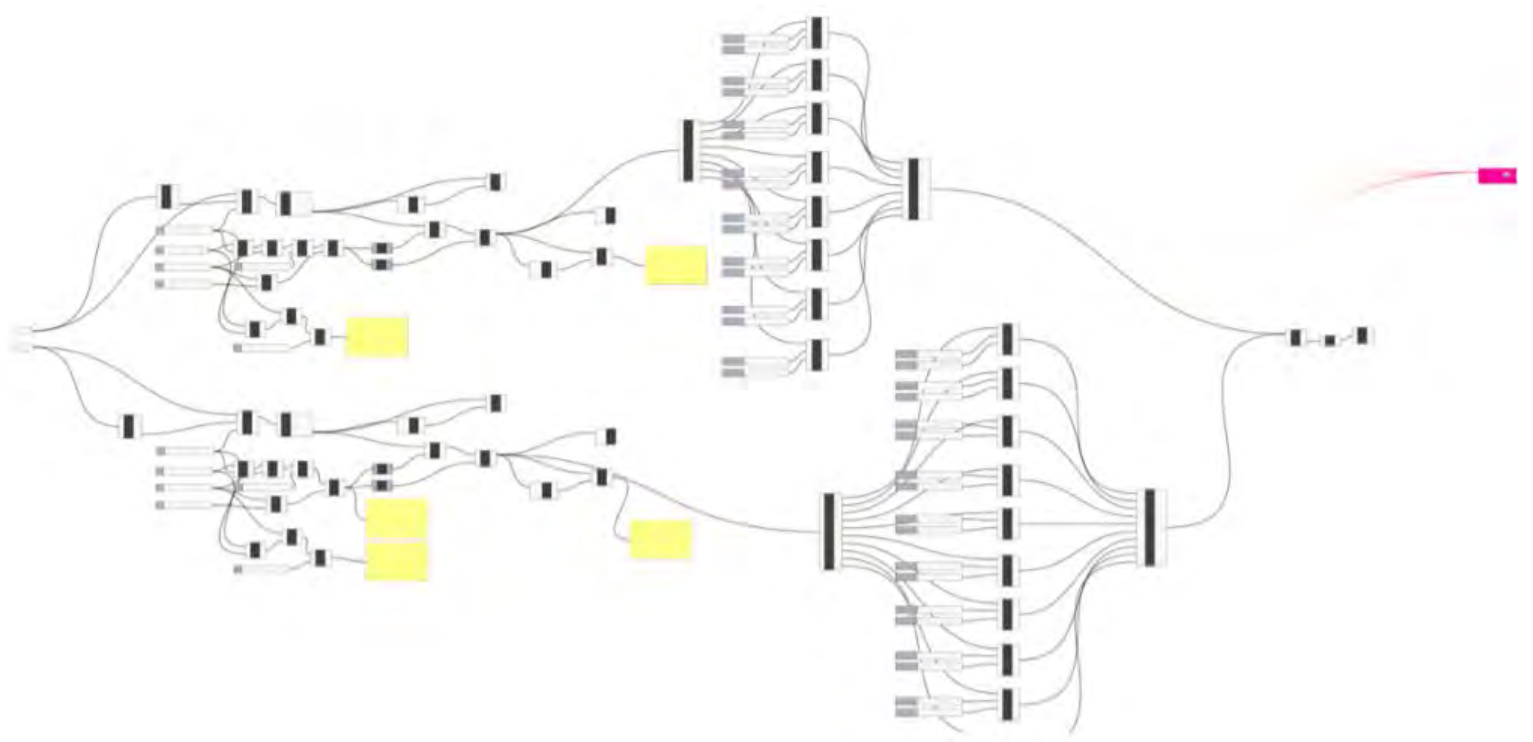

Figure 9. Script of connectivity optimizing

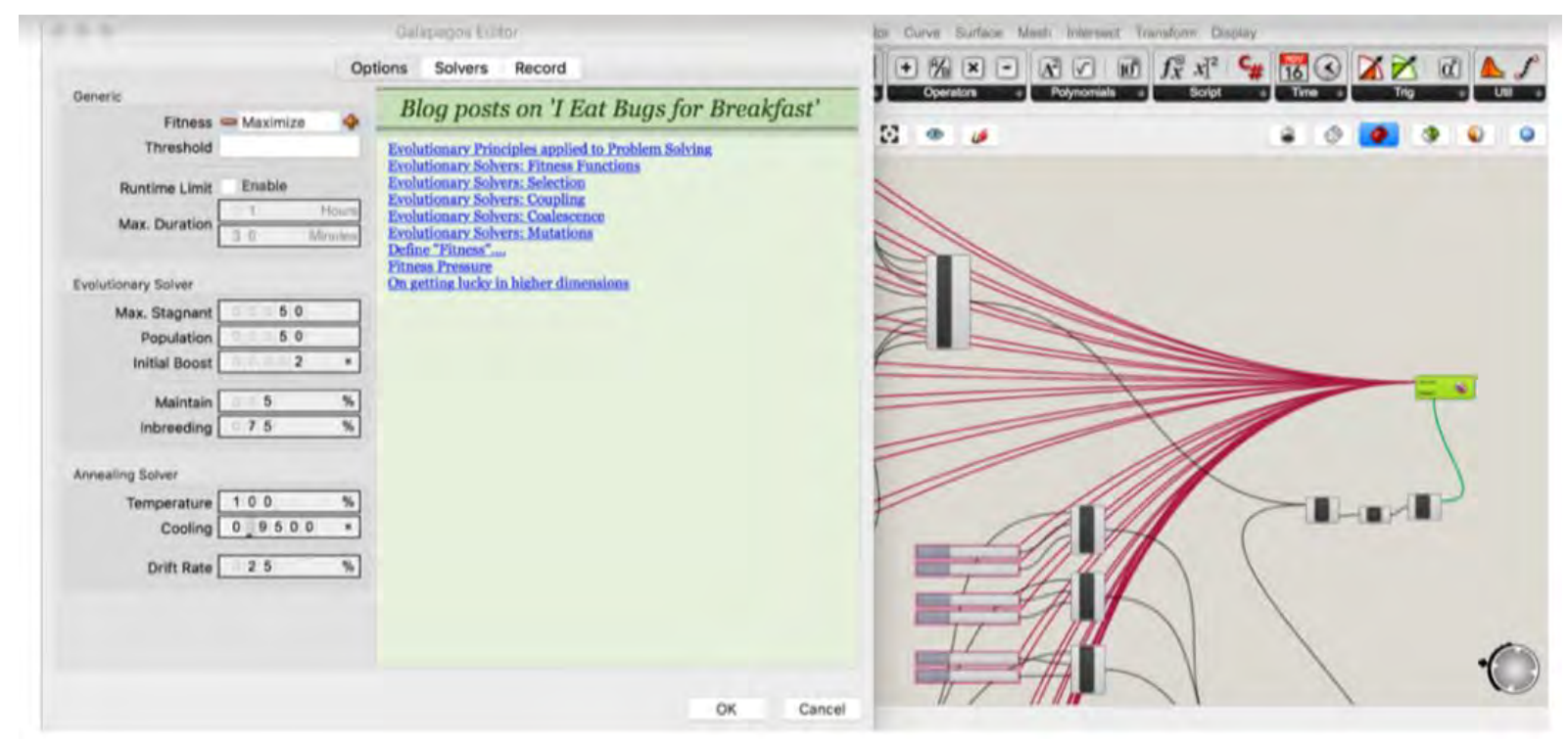

Figure 10. Options provided by Galapagos

According to the setting of the Fitness type, the pop-up screen of Galapagos Solvers provides four data-analysing parts (Figure 11). The yellow line chart on the top of the screen reflects the tolerance degree. When the data-line of right side becomes stable, the value is nearly the optimum solution. For example, if the Fitness is set as Maximize, the model presents a relatively maximize routes when the data-line is stable at one value. In the underneath part, the point and line figures represent the measures of variability; the numbers represent the tolerance values (Zhang and Schnabel, 2017).

For underground level, the space usage is simulated according to the transect zone type subdivision and existing underground exploitation. Based on the local Government's guidance, the underground pedestrian corridors of Tsim Sha Tsui will be extended from the current Tsim Sha Tsui Metro - Tsim Sha Tsui Metro East system to the Tsim Sha Tsui Metro - Tsim Sha Tsui East - Guangdong Road system. The underground area under Kowloon Park has the priority on the project lists. According to the zoning concept of Form-Based Code, the underground Kowloon Park belongs to the zone in approximate rectangle shape. The paper uses the undergroudn zone of Kowloon Park as a modelling example to test the possible space usage. 


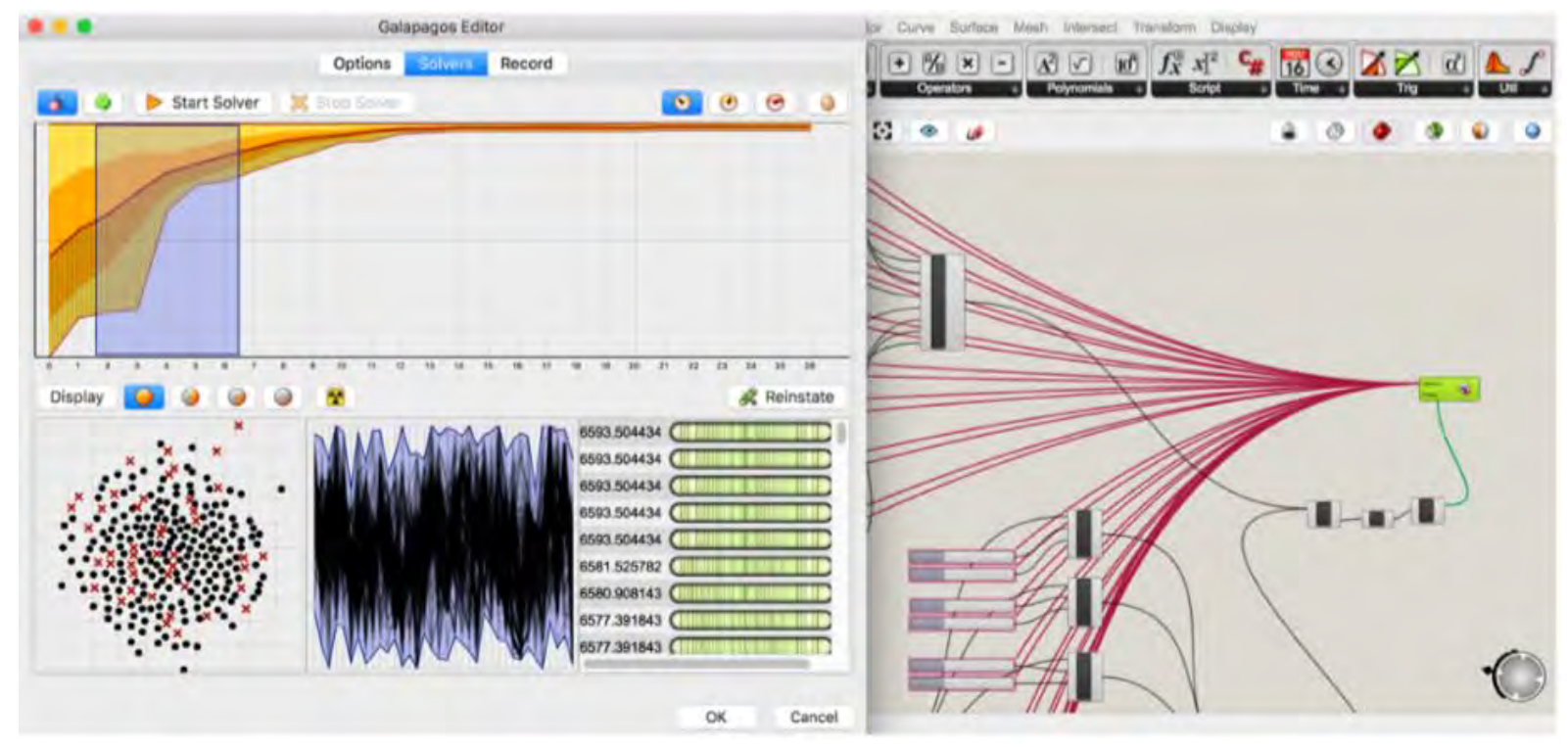

Figure 11. Solvers provided by Galapagos

Assuming there are random nodes in the underground site, each node represents a specific function component, such as underground shops, gathering points, public art show, or toilets. Since no subway transfer requirement in this zone, the use of underground space is mainly for extending open space, creating a social place and duplicating walkable streets. Programming the nodes by parametric script, the relatively appropriate locations of the functions can be decided taking advantage of Solvers (Figure 12). Through programming in Grasshopper, the connectivity between nodes can be measured by Maximum or Minimum Fitness. The results help Form-Based Code to decide the plan of space usage.

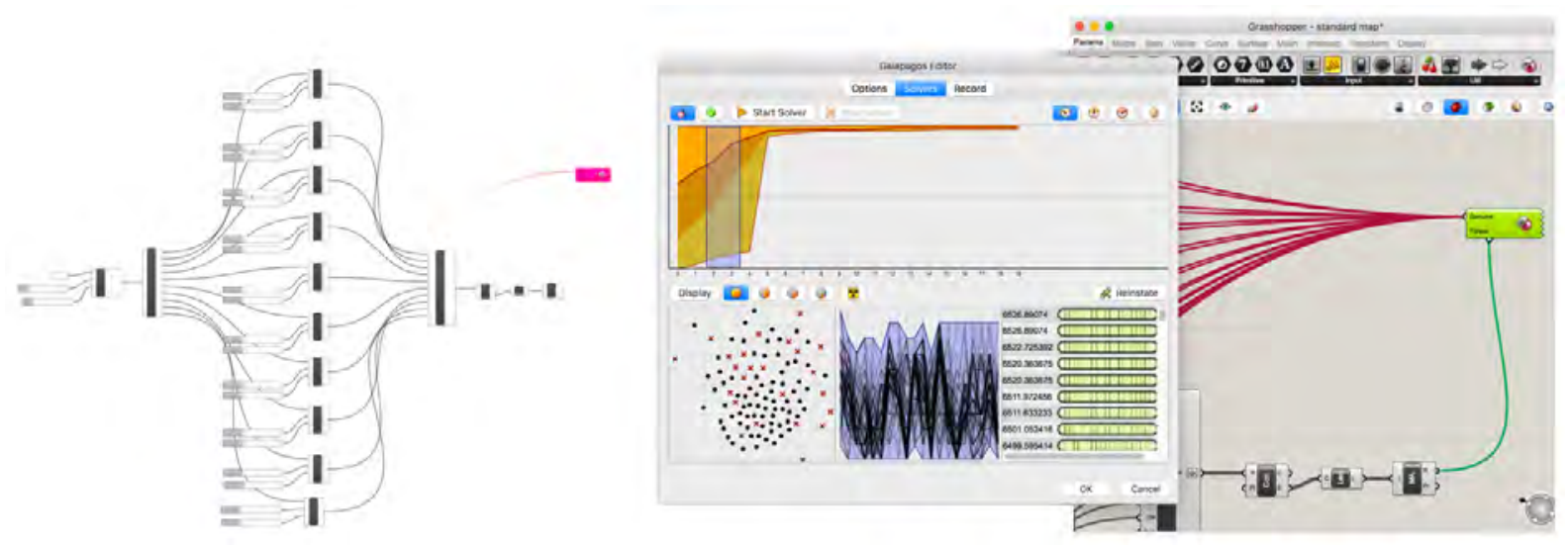

Figure 12. Solvers provided by Galapagos (underground)

Vertical movement convenience works to measure the volumetric space usage. The parametric platform allows Form-Based Code team to simulate people's activities in the vertical direction and calculate relatively short conversion paths. The programming in Grasshopper 3D provides possible vertical routes both inside and outside buildings (Figure 13). The red lines represent walking paths. Red boards are simulated connections inside or between buildings. Through Galapagos, it can be calculated which routes are shortest between different function nodes. For releasing large pedestrian flow in the vertical direction, shorter path means more convenient transportation. Main approaches to practice the vertical transportation are elevators, stairs and slopes.

Manipulating Galapagos works to simulate node connectivities in the parametric modelling at the conceptual stage of Form-Based Code. Possible zoning results are simulated by flexible manipulation of parameters and components. Further details of constructing vertical connections and underground space need deeper analyse in downstream architecture and urban design. 

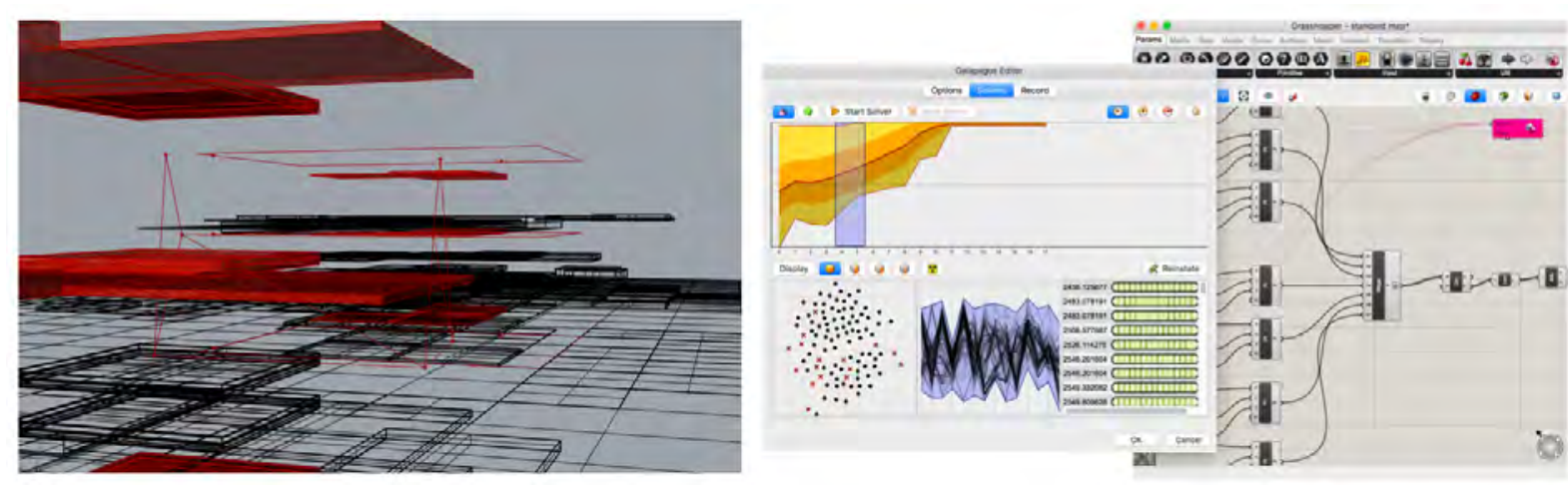

Figure 13. Solversprovided by Galapagos (above ground)

\section{Discussion and Conclusion}

This paper provides a demonstration that parametric methodology has the technical capability to support FormBased Code evaluation in a high-density environment. Using Tsim Sha Tsui, Hong Kong as the experimental site, the parametric Form-Based Code provides an alternative approach to zoning.

Form-Based Code usually uses graphic language to describe urban regulations and provisions. It converts texts and tables to images. Although the generation methodology is different from conventional zoning, the original Form-Based Code mainly relies on manually drawn. Generation and modification are cumbersome especially in large-scale urban projects. For real implementations, it is common that different variables are related to each other to define a place. Modifying one variable causes changes to other variables. Manually modification increases workload. Introducing parametric thinking makes the generation and modification process more automated. FormBased Code team can receive a series of performance feedbacks by changing the target parameters. In addition, parametric modelling instruments, such as Grasshopper 3D, provides evaluation-related components to automatically calculate extremum value. Programming these components, the software simulates activity routes between geometries. Parametric thinking facilitates Form-Based Code by integrating generation, modification and evaluation in one modelling process.

Form-Based Code makes it possible to generate mix-used urban space through weakening land-use division and strengthening form partition. When attempting Form-Based Code in Tsim Sha Tsui, it appears to be an effective and viable option to predict zoning results before implementing in real projects. Form-Based Code is related to floor area ratio, average pavement width, road hierarchy, infrastructure, the depth-width ratio of streets, and max height. Defining the requirements of these variables, a series of zone types are generated to describe the unique space characteristics of the experimental site. With an expected physical outcome, Form-Based Code provides models about what the future urban space looks like. Connectivity is a basic requirement for volumetric cities like Hong Kong in terms of high-density transportation flow, block permeability, and diverse functional areas. Hong Kong already has a highly-developed connective urban system. This paper employs parametric simulation to evaluate the connectivity of Form-Based Code models. The evaluation results provide possible spatial streamlines in the volumetric morphology. The connectivity evaluation supports the enhancement of the pedestrian connection to improve the walking environment performance.

This research creatively conducts an experiment that examining Form-Based Code in a volumetric morphology of high-density cities in Asia. There is clearly more explorations and deliberations to be done in the area of Form-Based Code analysis, such as the cooperation between Form-Based Code and established zoning system. We can conclude that Form-Based Code has potential to implement effectively in high-density cities, supporting local urban planning and design departments, developers, and householders' efforts to address the challenges of high-density development and build an amenity living place. 


\section{References}

1. Boeing, G., Daniel, C., Haley, H., Julie, M., \& Lili, R. (2014). LEED-ND and liveability revisited. Berkeley Planning Journal,27, 31-55. Retrieved from https://escholarship.org/uc/item/49f234rd\#author.

2. Bohl, C. C., \& Plater-Zyberk, E. (2006). Building community across the rural-to-urban transect. Places, $18(1), 4-17$.

3. Bum Kim, J., Clayton, M. J., \& Yan, W. (2011). Parametric Form-Based Codes: Incorporation of Land-use Regulations into Building Information Models. Canada: The University of Calgary.

4. Congress for the New Urbanism. (2016). What is New Urbanism? Retrieved from https://www.cnu.org/res ources/what-new-urbanism

5. Davis, D. (2013). A history of parametric. Retrieved from http://www.danieldavis.com/a-history-of-parame tric

6. Duany Plater-Zyberk \& Company. (1980). Seaside Florida project. DPZ projects. Retrieved from https://w ww.dpz.com/projects/all

7. Duany Plater-Zyberk \& Company. (2007). SmartCode version 9.2. Retrived from http://curis.msstate.edu/p ublish/3000-BookletSC.pdf[N.Q1]

8. Form-Based Code Institute. (2014). Form-Based Code Definition. Retrieved from http://formbasedcodes.or g/definition.

9. Frost, R. T. (1958). The trouble with zoning. National Municipal Review, 47(6), 275-278.

10. Inniss, L. B. (2007). Back to the Future: Is Form-Based Code an Efficacious Tool for Shaping Modern Civic Life. U. Pa. JL \& Soc. Change, 11, 75 .

11. Jabi, W. (2013). Parametric design for architecture. London: Laurence King.

12. Kan, C. H. (2012). Form-based urban planning code and its implications in Hong Kong. HKU Theses Online (HKUTO).

13. Lemar, A. S. (2015). Zoning as Taxidermy: Neighborhood Conservation Districts and the Regulation of Aesthetics. Ind. LJ, 90, 1525.

14. Parolek, D. G., Parolek, K., \& Crawford, P. C. (2008). Form based codes: a guide for planners, urban designers, municipalities, and developers. John Wiley \& Sons.

15. Schnabel, M. A., Zhang, Y., \& Aydin, S. (2017). Using parametric modelling in form-based code design for high-dense cities. Annual Symposium on Simulation for Architecture and Urban Design, 180, 265-272. Toronto: The University of Toronto

16. Shelton, B., Karakiewicz, J., Kvan, T. (2011). The making of Hong Kong: from vertical to volumetric. New York: Routledge.

17. Southworth, M. (2005). Designing the walkable city. Journal of Urban Planning and Development,131, 246-257.

18. Steuteville, R. (2009). The Transect. Retrieved from https://www.cnu.org/publicsquare/transect

19. Woodbury, R. (2010). Elements of parametric design. New York: Routledge.

20. Zhang, Y., \& Schnabel, A. M. (2017). (A. M. Schnabel, Ed.). 51st International Conference of the Architectural Science Association, 139-148. Wellington: Victoria University of Wellington. 